\title{
Deprenyl in Parkinson's Disease: Mechanisms, Neuroprotective Effect, Indications and Adverse Effects
}

\author{
Paul Vezina, Erich Mohr and David Grimes
}

\begin{abstract}
Deprenyl is a synthetic, selective inhibitor of the monoamine oxidase-B enzyme system. The mechanism of its beneficial effect in early and advanced Parkinson's disease is not settled. Increased striatal dopamine accumulation, sensitization of surviving dopamine neurons with increased dopamine production and reduced nigro-striatal toxicity may all contribute. The standard daily dose of deprenyl is $10 \mathrm{mg}$. Selectivity may be lost at higher doses. Deprenyl is especially indicated in untreated patients, improving up to 50 percent of patients with mild motor fluctuations. Major symptomatic benefit also occurs in occasional levodopa treated patients. Adverse effects are common, however. Increase dyskinesias, confusion and hallucinations, nausea and postural hypotension may necessitate drug withdrawal or the use of low dose regimens. Caution should be exercised with older patients, those with ulcer disease, which may be worsened by deprenyl, and individuals with active ischemic heart disease where the safety of this drug is not yet clear.
\end{abstract}

RÉSUMÉ: Le déprényl dans la maladie de Parkinson: mécanismes, effet néoprotecteur, indications et effets secondaires. Le déprényl est un inhibiteur synthétique sélectif du système enzymatique de la monoamine oxydase-B. Le mécanisme par lequel il exerce un effet favorable sur la maladie de Parkinson, taut au début qu'en phase avancée de la maladie, n'est pas établi. Une augmentation de l'accumulation de la dopamine striatale, la sensibilisation des neurones dopaminergiques résiduels entraînant une production accrue de dopamine et une diminution de la toxicité nigrostriée sont tous des éléments qui peuvent y contribuer. La dose quotidienne standard de déprényl est de $10 \mathrm{mg}$. La sélectivité peut être perdue à plus haute dose. Le déprényl est particulièrement indiqué chez les patients non traités, avec un bénéfice chez pas moins de $50 \%$ des patients qui ont des fluctuations motrices discrètes. Certains patients traités par la lévodopa peuvent également en retirer un bénéfice symptomatique important. Cependant, les effets secondaires sont fréquents. Une augmentation des dyskinésies, de la confusion et des hallucinations, des nausées et de l'hypotension orthostatique peuvent nécessiter l'arrêt de la médication ou une réduction de la posologie. On doit être prudent chez les patients âgés, chez ceux qui ont une maladie ulcéreuse, qui peut être exacerbée par le déprényl, et chez les individus porteurs d'une maladie coronarienne active, la sécurité de cette médication n'étant pas établie chez ce groupe de patients.

Can. J. Neurol. Sci. 1992; 19: 142-146

Deprenyl is a synthetic, selective inhibitor of the monoamine oxidase B (MAO-B) enzyme system that is now widely used in the treatment of Parkinson's disease. The mechanism of its beneficial effect in early and advanced disease is not settled. Enhanced dopamine and possible amphetamine effects are suggested but the degree of sensitivity of the abnormal parkinsonian brain to these effects is not well understood. Deprenyl clearly does not halt the progression of Parkinsonism, but there is strong optimism that it may retard the progression. ${ }^{1.2 .3}$ It has been proposed to achieve this effect by retarding the degeneration of dopamine neurons. There is evidence to suggest that it may also act by producing sensitization in surviving dopamine neurons.
A sophisticated, 800 patient, double-blind cross over study with deprenyl and tocopherol in untreated Parkinson's disease patients has given support to the view that deprenyl retards the progression of the disease. ${ }^{2}$ The planned longterm followup of this 800 patient cohort will yield more definite information on the protective effect of deprenyl in levodopa-untreated patients and will also show whether the drug decreases the incidence or severity of levodopa-related adverse effects. Deprenyl is indicated for its neuroprotective effect especially in untreated patients. At least fifty percent of patients with mild motor fluctuations will have benefit. ${ }^{4}$ Adverse effects with deprenyl are common, especially in levodopa-treated patients. Increased dyskinesias, confusion and hallucinations, nausea and postural hypotension,

From The Neurosciences Unit, Loeb Medical Research Institute and Division of Neurology, Ottawa Civic Hospital and the Institute of Mental Health Research, Royal Ottawa Hospital, University of Ottawa, Ottawa

Reprint requests to: Dr. Paul Vezina, Division of Neurology and Loeb Medical Research Institute, Ottawa Civic Hospital, 1053 Carling Ave., Ottawa, Ontario, Canada KIY 4E9 
all may necessitate drug withdrawal. The drug should be used cautiously and in lower doses in older patients.

\section{Mechanism of Action of Deprenyl}

The beneficial effects of deprenyl have generally been ascribed to two actions of this drug. On the one hand, it is assumed that MAO-B inhibition produces an increase in dopamine at nigro-striatal dopamine neuron terminals in the striatum (thus accounting for symptomatic relief). On the other, it has been proposed that deprenyl may interfere with the underlying pathogenetic mechanisms of Parkinson's disease and thereby slow down the progression of the disease. ${ }^{5}$ Support for the latter view comes from evidence that MAO-B is responsible for MPTP ( 1 -methyl-4-phenyl-1,2,3,6-tetrahydropyridine) toxicity (by oxidizing it to MPDP, 1-methyl-phenyl-dihydropyridinium, which spontaneously oxidizes to MPP+, l-methyl-phenylpyridinium) or the generation of free radicals and hydrogen peroxide that result from the oxidation of dopamine $e^{6.7}$ and is encouraged by the finding that deprenyl significantly delays the onset of disability and need for L-DOPA therapy. ${ }^{2}$ While such findings are exciting and must be pursued, it should also be noted that in the Datatop study, no beneficial effect from tocopherol, a biologically active component of vitamin $E$ which acts as an antioxidant, has yet been found. ${ }^{2}$ Furthermore, while there is no doubt as to the ability of MPTP to kill dopamine neurons, no commonly occurring environmental toxin that is structurally similar to MPTP and that is equally lethal as yet been found.

As indicated above, the view that deprenyl simply provides symptomatic therapy comes from the logical expectation that more dopamine will be available if catabolism is inhibited. It is not clear, however, how this translates into higher levels of extracellular dopamine. The fact that the main metabolites of deprenyl are amphetamine and methamphetamine (although, the less active isomers $)^{8}$ and that deprenyl has been reported to increase concentrations of phenylethylamine, an endogenous trace amine with dopamine releasing effects, ${ }^{9}$ could provide some possible mechanisms whereby increased levels of intracellular dopamine could be released into the synaptic cleft. Other findings, however, do not support this possibility. Thus, deprenyl has been found to have no effect in narcolepsy and to be without stimulant effects in normal human controls ${ }^{10}$ or to elicit increased locomotion in rats."

Knoll and his colleagues have conducted numerous experiments to investigate the mechanism of action of deprenyl on dopamine neurons. They reported that while an acute injection of the drug had no effect on dopamine turnover ${ }^{12}$ and release ${ }^{13,14}$ in striatal regions, repeating these injections daily for 7,14 or 21 days produced increases in these measures of dopamine transmission. This is consistent with clinical reports on the use of deprenyl and other MAO-B inhibitors in the treatment of depression. ${ }^{15}$ These findings were interpreted as support for the idea that deprenyl facilitates the activity of nigro-striatal dopamine neurons and that this facilitation was linked to an increase in the firing rate of these neurons. While it is clear that increased cell firing would provide the stimulus for exocytosis of the dopamine accumulated by intracellular MAO-B inhibition in the neuron terminal, ${ }^{16,17}$ it is less clear why the conditions for increased dopamine transmission would not be manifest acutely but only after repeated exposure to deprenyl. Furthermore, dif- ferent histochemical studies have indicated that MAO-B is concentrated in serotonergic neurons and in glia while catecholaminergic neurons stain positively for MAO-A. ${ }^{18.19}$ It is true that inhibition of extracellular MAO-B could favor the accumulation of released dopamine $\mathrm{e}^{20}$ but this, by itself, would not explain increasing dopamine transmission with repeated exposure to deprenyl. It has been known for some time that manipulations such as repeated amphetamine, which repeatedly produce increased levels of extracellular dopamine, sensitize dopamine neurons so that subsequent manipulations produce even greater increases in extracellular dopamine. ${ }^{21}$ It is intriguing to speculate that, sensitization of surviving dopamine neurons may provide another possible mechanism in addition to speculated neuroprotection, whereby repeated exposure 10 deprenyl retards the need for dopamine replacement therapy.

\section{Neuroprotective Effects of Deprenyl}

The introduction of levodopa in the late 1960's completely changed the therapeutic approach to Parkinson's disease. ${ }^{22}$ The addition of dopamine agonist therapy 10 years later provided further benefit but, also, by this time the complications and limitations of replacement therapy were all too obvious. We are now a few years into a new treatment era with the consideration that progressive nigral degeneration may be related to controllable oxidative-mediated mechanisms. ${ }^{23}$

The basic premise of the Datatop study was that exogenous or endogenous nigral neuronal toxicity may be reduced with antioxidative therapy. This 800 patient double-blind, placebo controlled study has shown that deprenyl ( $10 \mathrm{mg}$ per day) delays the need for Sinemet treatment by 57 percent. $^{2}$ A similar study of 54 patients produced results that support the Datatop study conclusions. ${ }^{24}$

It has been suggested that the delay in requirement for levodopa treatment seen in the Datatop study may have been related to a symptomatic effect of deprenyl therapy. ${ }^{25}$ However, there is no well documented study of significant size that shows a clinically significant symptomatic effect of deprenyl in levodopa untreated patients. ${ }^{26}$ After a double-blind placebo controlled cross-over study, Teravainen concluded that deprenyl without concomitant levodopa does not significantly increase brain dopamine concentration and the ten percent symptomatic improvement on deprenyl was clinically insignificant. ${ }^{27}$ In this context, it is interesting to note that a clinical trial with a new dopamine agonist showed up to 20 percent improvement in placebo treated patients. ${ }^{28}$ Laboratory studies have shown that deprenyl does not elicit an acute increase in dopaminergic activity. ${ }^{29}$ Clinical experience with deprenyl has also shown that there is much less symptom worsening on drug withdrawal when compared with other second line antiparkinsonian agents including anticholinergics, amantadine or low dose bromocriptine.

Fifteen months after enrollment was closed, the Datatop study was altered because of the significant finding that deprenyl delayed the need for levodopa therapy. After suitable observation for washout effect, all patients continuing in the study were placed on active deprenyl in addition to previous placebo or tocopherol therapy. ${ }^{3}$

Patients in the Datatop study will be followed up to five years. The design details of the study have been previously published. ${ }^{30}$ The longterm followup of these patients will allow the 
possibility for a multitude of new observations to be made both on the natural development of Parkinson's disease and on the longterm effects of deprenyl therapy both with and without levodopa. In this cohort of patients, the following will be possible.

- Deprenyl treated "survivors" who have not yet required levodopa will be observed.

- Any possible protective effects of tocopherol or the combination of deprenyl and tocopherol in levodopa untreated patients will be seen.

- The question of whether deprenyl, or deprenyl and tocopherol, can influence the course of levodopa treated Parkinson's disease will be answered.

- Will the use of these agents decrease the incidence and severity of motor fluctuations, dyskinesias or mental adverse effects?

- Can the incidence and severity of dementing symptoms or other cognitive changes be reduced?

- Will the early combination of deprenyl, Sinemet and a dopamine agonist lead to reduced levodopa treatment complications?

- The initial and followup spinal fluid studies with prolonged washout time may possibly show a reduced decline in monoamine metabolites.

The multiple followup phases in the Datatop study will also allow for further detailed observation of possible symptomatic effects of deprenyl. Data from three wash-in and two wash-out periods will be available. Another study is also underway in the United Kingdom to assess the longterm effect of deprenyl on the course of Parkinson's disease. ${ }^{31}$ This study has three arms: patients will be treated with levodopa alone, levodopa plus deprenyl and levodopa plus low dose bromocriptine.

\section{Indications for and Use of Deprenyl in the Treatment of Parkinson's Disease}

Despite the ongoing discussion of protective versus symptomatic effect, few neurologists would argue with the recommendation to use deprenyl in all newly-diagnosed, mildly disabled patients, even before the use of levodopa. This is the first suggestion in a neurodegenerative disease, that an agent may alter disease progression. In this age of better-informed and participating patients, the use of deprenyl seems mandatory in all newly-diagnosed patients. In this situation, standard practice is to give $5 \mathrm{mg}$ morning and noon.

Indication for, and dosage of deprenyl in levodopa-treated patients is less clear. The response seems to be independent of the duration of previous levodopa treatment. ${ }^{32}$ About one-half of patients with end-of-dose failure will have symptomatic benefit. The beneficial effect may not last one year. ${ }^{33}$ Deprenyl is very compatible with bromocriptine and the combination of levodopa-bromocriptine plus deprenyl may give further improvement in motor fluctuations. Marked improvement has also been reported in patients with nocturnal and early morning akinesia. ${ }^{4}$ Sudden "on-off" motor fluctuations are not relieved. ${ }^{4}$ The degree of improvement with the addition of deprenyl in most levodopa patients is moderate to minimal. ${ }^{34}$ Occasional patients will have major symptomatic benefit.

At the modest dosage used in Parkinson's disease, deprenyl is felt not to have a statistically significant antidepressant effect. ${ }^{35}$ Some observers have reported an improved antidepres- sant effect when deprenyl is added to a small dose of a tricyclic antidepressant. In addition, the possible effect of deprenyl on cognitive dysfunctions is being explored. Increases in central nervous system MAO-B activity and lipid peroxidation have been reported in Alzheimer's disease, which further supports the hypothesis that cytotoxic monoamine metabolites or free radicals may accelerate neuronal death. ${ }^{36.37}$

Deprenyl irreversibly inhibits the activity of MAO type B in both the brain and periphery. ${ }^{38}$ New enzyme activity requires new synthesis of MAO-B. Recovery of one-half of enzyme activity has been reported to take between 10 and 30 days in animal studies. ${ }^{39}$ This information suggests that less frequent administration of deprenyl might reduce side effects without loss of therapeutic benefit. The standard daily dosage of deprenyl is $10 \mathrm{mg}$ given in two divided doses. In patients who are likely to have adverse effects, a starting regimen of $2.5 \mathrm{mg}$ deprenyl every second day should be considered. Despite the very long duration of action of deprenyl, most patients take two daily doses. This is probably more related to the method of drug introduction rather than pharmacological effect.

Birkmayer has stated that deprenyl prolongs life expectancy in Parkinson's disease patients, ${ }^{40}$ but this uncontrolled observation was not supported by the results of another study.' Animal studies have suggested that deprenyl may inhibit the aging process in the striatum. ${ }^{41}$ In this context, it is of interest to note that levodopa did not reverse the motor defects of normal aging in a small series of non-parkinsonian patients. ${ }^{42}$

\section{Adverse Effects and Cautions in the Use of Deprenyl}

Adverse effects with deprenyl use in Parkinson's disease patients are common. The incidence of adverse effects is increased in levodopa-treated patients. The majority of adverse events are relatively minor and reversible and the drug has proven to be remarkably safe over many years of longterm use. . $^{1,431.43}$

Confusion and hallucinations are common. This occurs more often in patients who have had this problem with other antiparkinsonian agents or already have sleep upset and benign hallucinations. Symptomatic control of these drug-induced complications may be possible with receptor-specific antagonists. Special care must be given in using deprenyl in older patients and in patients with very advanced disease. In this situation the lower dose treatment regimen outlined previously should be considered. If patients develop sleeplessness, anxiety, hyperactivity and inability to relax, the dose of levodopa should be reduced.

When deprenyl is being added in levodopa-treated patients, the standard practice is not to decrease levodopa before adverse effects occur. The most common adverse effect is an increase in dyskinesias. Patients should be given written instructions to decrease levodopa when this occurs. Levodopa reduction varying from 10 to 30 percent is frequently necessary, but even then, deprenyl may have to be withdrawn.

Nausea may occur in up to 20 percent of patients treated with levodopa and deprenyl. ${ }^{44}$ It is usually transient and clears within a few weeks but may be very distressing initially. Nausea sometimes occurs when levodopa-carbidopa is being added to deprenyl $10 \mathrm{mg}$ daily in mildly disabled patients. In this situation, reducing deprenyl to $5 \mathrm{mg}$ daily may clear the nausea and allow for an adequate therapeutic dose of levodopa. 
The blood pressure elevation related to the monoamine oxidase-A mediated tyramine (cheese) effect is not seen when deprenyl is used at a dose of $10 \mathrm{mg}$ daily. Dietary restrictions are not necessary. Patients should be cautioned not to use overthe-counter cold medications because of the risk of large doses of exogenous amines. Postural hypotension is a more frequent and bothersome symptom when deprenyl is used in combination with levodopa. Some increase in pulse has been recorded in clinical studies using depreny ${ }^{27}$ and postural dizziness and symptomatic postural hypotension are common. This may be seen as an initial symptom or as an aggravation of already existing levodopa-induced postural lowering of blood pressure.

Deprenyl appears to be safe to use in patients with ischemic heart disease. Aggravation of angina has been reported in occasional patients. However, this has been infrequent and a clear cause and effect relationship is not established. Amphetamines can aggravate or cause myocardial ischemia, although it does not appear that significant amounts of amphetamine are produced during deprenyl metabolism. ${ }^{45-47}$

Patients with active peptic ulcer should not take deprenyl. Augmented histamine release has been reported, and severe upper gastro intestinal bleeding has occurred. ${ }^{48}$

Transient headaches have been reported in some patients and pre-existing migraine has been aggravated.

While insomnia has been reported to occur, it is usually transient. It frequently responds to moving doses of deprenyl earlier in the day. As it appears an amphetamine effect from deprenyl is unlikely ${ }^{47,49}$ the insomnia is probably related to an increase in dopamine. Deprenyl has not been effective in narcolepsy. ${ }^{10}$

Mild elevation of alkaline phosphatase has been reported in some patients. ${ }^{33}$ These patients, however, were on other drugs and no consistent hepatic abnormality has been documented from deprenyl. ${ }^{43}$ Routine followup blood work on deprenyl-only treated patients does not seem indicated.

Non-selective monoamine oxidase inhibitors are stopped before surgery. It seems prudent at this early stage to stop deprenyl at least three or four days before surgery but this may not be necessary. This may be more relevant for major procedures where pressor drugs like dopamine may be required. Monoamine oxidase inhibitors are contraindicated for use with Meperidine and it seems wise to avoid using deprenyl with this drug.

Non-selective monoamine oxidase inhibitors should not be used with tricyclic antidepressants because of the risk of hyperpyrexic reactions. Clinical experience suggests that it is quite safe to use deprenyl with tricyclic antidepressants and indeed these two agents may have an additive beneficial effect. Unnecessary withdrawal of tricylics while introducing deprenyl has led to serious depressive reactions.

Fluoxetine and deprenyl should not be used together. Serious adverse reactions have been reported including mania and a serotonin-like syndrome, characterized by hypertension and sweating. ${ }^{50}$ Fluoxetine has also been reported to aggravate parkinsonism in non-deprenyl treated patients. ${ }^{51}$

Deprenyl is a useful drug in Parkinson's disease and its introduction has generated much optimism. Longterm follow-up of deprenyl-treated patients will reveal whether it definitely retards the progression of the disease and reduces the frequency and severity of levodopa related complications. Further definition of its mechanisms of action is needed and appropriate studies are now underway in different laboratories. It is hoped in this way to clarify the possible neuroprotective and dopaminergic sensitizing effects of deprenyl. The incidence and severity of adverse effects can be reduced with careful attention to the clinical details outlined in this review.

\section{ACKNOWLEDGEMENTS}

The Parkinson's disease research program at the Ottawa Civic Hospital is supported by the Parkinson's Society of Ottawa-Carleton and Dr. Vezina occupies a Chair endowed by the Geoffrey H. Wood Foundation. The authors thank Ms. Gayla Desjardins for the preparation of the manuscript.

\section{REFERENCES}

1. Elizan TS, Yahr MD, Moros DA, et al. Selegiline as an adjunct to conventional levodopa therapy in Parkinson's disease. Arch Neurol 1989; 46: 1280-1283.

2. The Parkinson Study Group. Effect of deprenyl on the progression of disability in early Parkinson's disease. N Engl J Med 1989; 321: 1364-1371.

3. Shoulson I. Protective therapy for Parkinson's disease. $I n$ : Koller WC, Paulson G, eds. Therapy of Parkinson's disease. New York: Dekker, 1990; 357-368.

4. Lees AJ, Shaw KM, Kohout LJ, et al. Deprenyl in Parkinson's disease. Lancet 1977; 2: 791-795.

5. Birkmayer W, Knoll J, Riederer PJ. Increased life expectancy resulting from addition of deprenyl to Madopar treatment in Parkinson's disease. Neural Transm 1985; 65: 113-127.

6. Cohen G, Spina MB. Deprenyl suppresses the oxidant stress associated with increased dopamine turnover. Ann Neurol 1989; 26: 689-690.

7. Furtado JCS, Mazurek MF. MPTP-induced neurotoxicity and the quest for a preventative therapy for Parkinson's disease. Can J Neurol Sci 1991; 18: 77.

8. Reynolds GP, Elsworth JD, Blau K, et al. Deprenyl is metabolized to methamphetamine and amphetamine in man. Br J Clin Pharmacol 1978; 6: 542.

9. Paterson IA, Juorio AV, Boulton AA. Possible mechanisms of action of deprenyl in parkinsonism. Lancet 1990; 336: 183.

10. Schachter M, Price PA, Parkes JD. Deprenyl in narcolepsy. Lancet 1979; 1: 831-832.

11. Mantegazza P, Riva MJ. Amphetamine-like activity of B-phenethylamine after a monoamine oxidase inhibitor in vivo. Pharm Pharmacol 1963; 15: 472-478.

12. Knoll $\mathrm{J}$. The possible mechanism of action of (-)deprenyl in Parkinson's disease. J Neural Transm 1978; 43: 117.

13. Zsilla G, Foldi P, Held G, et al. The effect of repeated doses of ()deprenyl on the dynamics of monoaminergic transmission. Comparison with clorgyline. Pol J Pharmacol Pharm 1986; 86: 211-217.

14. Kerecsen L, Kalasz H, Tarcail J, et al. Measurement of DA and DOPAC release from rat striatal preparations in vitro using HPLC with electrochemical detection. In: Kalasz and Ettre, eds. Chromotography: the State of the Art. Budapest: Akademiai Kiado, 1985.

15. Mann JJ, Gershon S. Deprenyl, a selective monoamine oxidase type B inhibitor in endogenous depression. Life Sci 1980; 26: 877-882.

16. Knoll J. Role of B-type monoamine oxidase inhibition in the treatment of Parkinson's disease. In: Shah and Donald, eds. Movement disorders. New York: Plenum, 1986.

17. Glover V, Sandler M, Owen F, et al. Dopamine is a monoamine oxidase B substrate in man. Nature 1977; 265: 80-81.

18. Westlund KN, Denney RM, Kochersperger LM, et al. Distinct monoamine oxidase $A$ and $B$ populations in primate brain. Science 1985; 230: 181-183.

19. Glover V, Willoughby J, Sandler M. Histochemical localization of MAO A and B in brain. Pharmacol Toxicol 1987; 60: S22.

20. Levitt P, Pintar JE, Breakefield XO. Immunocytochemical demonstration of monoamine oxidase $B$ in brain astrocytes and serotonergic neurons. Proc Natl Acad Sci 1982; 79: 6385-6389. 
21. Robinson TE, Becker JB. Enduring changes in brain and behavior produced by chronic amphetamine administration: a review and evaluation of animal models of amphetamine psychosis. Brain Res Rev 1986; 11: 157-198.

22. Marsden CD. Parkinson's disease. Lancet 1990; 335 (1): 948-952.

23. Grimes JD, Hassan MN, Thakar J. Antioxidant therapy in Parkinson's disease. Can J Neurol Sci 1987; 14: 483-487.

24. Tetrud JW, Langston JW. The effect of deprenyl (selegiline) on the natural history of Parkinson's disease. Science 1989; 245: 519522.

25. Kofman OS. Deprenyl: protective vs symptomatic effect. Can J Neurol Sci 1991; 18: 83-85.

26. Grimes JD. Deprenyl: the exciting possibility of protective effect. Can J Neurol Sci 1991; 18: 85-86.

27. Teravainen H. Selegiline in Parkinson's disease. Acta Neurol Scand 1990; 81: 333-336.

28. Diamond SG, Markham CH, Treciokas LJ, et al. Double-blind trial of pergolide in Parkinson's disease. Neurology 1985; 35: 291295.

29. Knoll J. Deprenyl (selegiline): the history of its development and pharmacological action. Acta Neurol Scand 1983; 95: 57-80.

30. Parkinson Study Group. Datatop: a multicentre controlled clinical trial in early Parkinson's disease. Arch Neurol 1989; 46: 10521060.

31. Lees AJ, Frankel J, Eatough FV, et al. Acta Neurol Scand 1989; 126: 139-145.

32. Birkmayer W, Riederer P, Ambrozi L, et al. Implications of combined treatment with Madopar and L-deprenyl in Parkinson's disease. Lancet 1977; 2: 439-443.

33. Golbe LI. Long-term efficacy and safety of deprenyl (selegeline) in advanced Parkinson's disease. Neurology 1989; 39: 1109-1111.

34. Rinne UK, Siirtola T, Sonninen VL. L-deprenyl treatment of on-off phenomenon in Parkinson's disease. J Neural Transm 1978; 43: 253-262.

35. Mann JJ, Fox-Aarons S, Wilner PJ, et al. A controlled study of the antidepressant efficacy and side effects of (-)deprenyl. Arch Gen Psychiatry 1989; 46: 45-50.

36. Adolfsson R, Gottfries CG, Wiberg A, et al. Increased activity of brain and platelet monoamine oxidase in dementia of the Alzheimer's type. Life Sci 1989; 27: 1029-1034.
37. Harman D. Role of free radicals in aging and disease. In: Johnson HA, ed. Relations between normal signs and disease. New York: Raven Press, 1985; 45-84.

38. Sandler M. Monoamine oxidase inhibitors and their pharmacological significance. Acta Neurol Scand 1983; 95: 37-41.

39. Goldstein M, Lew JY. Deprenyl for the treatment of early Parkinson's disease. N Engl J Med 1990; 21: 1526-1527.

40. Birkmayer W. Deprenyl (selegiline) in the treatment of Parkinson's disease. Acta Neurol Scand 1983; 95: 103-106.

41. Knoll J. The pharmacology of selegiline ((-)deprenyl). New aspects. Acta Neurol Scand 1989; 126: 83-91.

42. Newman RP, LeWitt PA, Jaffe M, et al. Motor function in the normal aging population: treatment with levodopa. Neurology 1985; 35: 571-573.

43. Heinonen EH, Rinne UK. Selegiline in the treatment of Parkinson's disease. Acta Neurol Scand 1989; 126: 103-111.

44. Golbe LI, Lieberman AN, Muenter MD, et al. Deprenyl in the treatment of symptom fluctuations in advanced Parkinson's disease. Clin Neuropharmacol 1988; 11: 45-55.

45. Furst SR, Fallon SP, Reznik GN, et al. Myocardial infarction after inhalation of methamphetamine. N Engl J Med 1990; 323: 1147. 1148.

46. Carson P, Oldroyd K, Phadke K. Myocardial infarction due to amphetamine. Br Med J 1987; 294; 1525-1526.

47. Heinonen EH, Myllyla V, Sotaniemi K, et al. Pharmacokinetics and metabolism of selegiline. Acta Neurol Scand 1989; 126: 93-99.

48. Saint-Hilaire M, Feldman RG, Durso R. Deprenyl for the treatment of early Parkinson's disease. N Engl J Med 1990; 322: 1527.

49. Stern GM, Lees AJ, Hardie RJ, et al. Clinical pharmacological problems of deprenyl (selegiline) treatment in Parkinson's disease. Acta Neurol Scand 1983; 95: 113-116.

50. Suchowersky O, deVries J. Possible interactions between deprenyl and prozac. Can J Neurol Sci 1990; 17: 352-353.

51. Bouchard RH, Pourcher E, Vincent P. Fluoxetine and extrapyramidal side effects. Am J Psychiatry 1989; 146: 1352-1353. 